Supporting Information

\title{
Growth of Bouquet-like $\mathrm{Zn}_{2} \mathrm{GeO}_{4}$ Crystal Clusters in Molten Salt and Understanding the Fast Na-Storage Properties
}

Jie Zhou, Wanqun Zhang, ${ }^{\dagger}$ Haoyu Zhao, ${ }^{\dagger}$ Jie Tian, ${ }^{\S}$ Zixuan Zhu, ${ }^{\dagger}$ Ning Lin, ${ }^{\dagger}$ and Yitai Qian $^{+}$

$\dagger$ Department of Applied Chemistry and $\$$ Chemistry Experiment Teaching Center, University of Science and Technology of China, Hefei, Anhui province, 230026, P. R. China.

$\S$ Experimental Center of Engineering and Material Science, University of Science and Technology of China, Hefei,Anhui 230026, P. R. China.

Corresponding authors: Ning Lin

Email:ning1@mail.ustc.edu.cn 

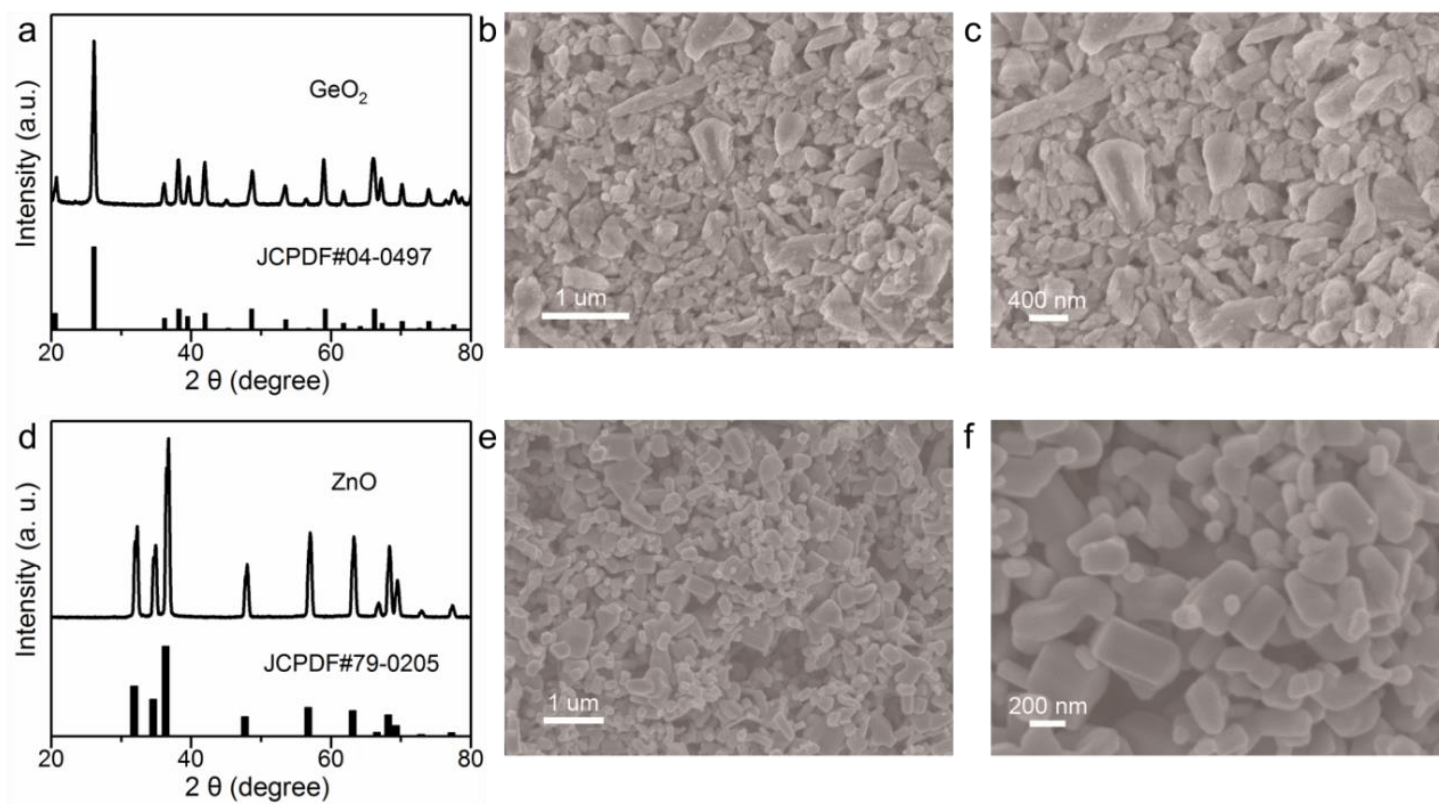

Figure S1. (a) XRD pattern (b-c) SEM images of raw materials $\mathrm{GeO}_{2}$ (d) XRD pattern (e-f)

SEM images of raw materials $\mathrm{ZnO}$.
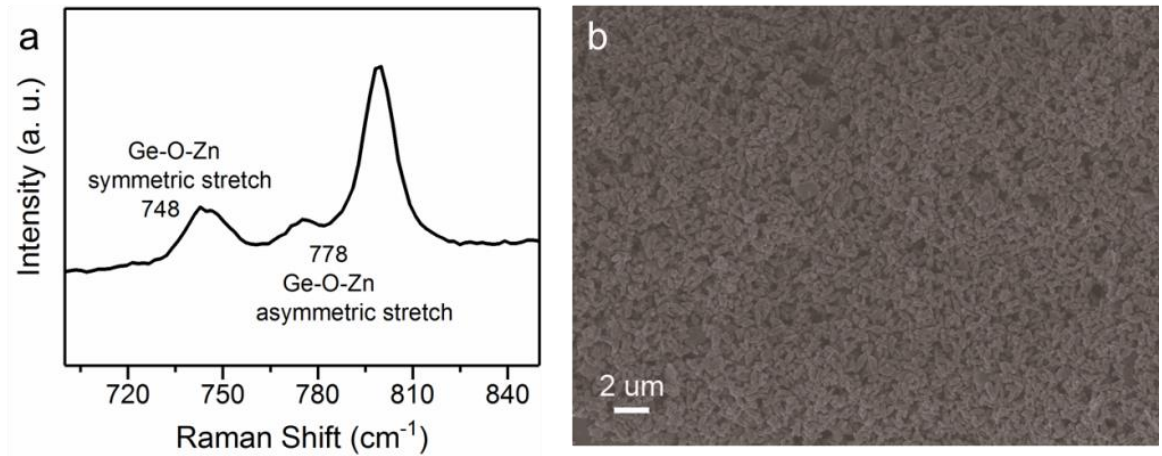

Figure S2. (a) Raman spectrum and (b) SEM image of $\mathrm{Zn}_{2} \mathrm{GeO}_{4}$ crystal clusters.
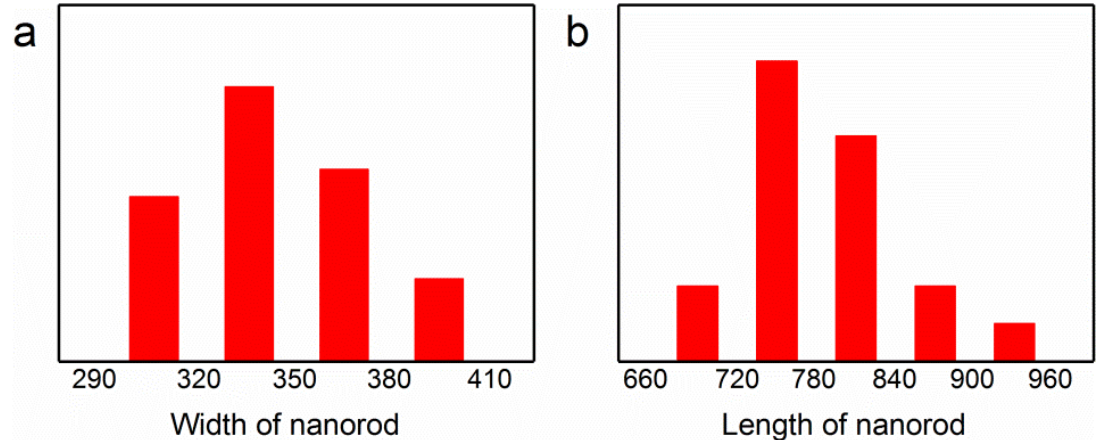

Figure S3. (a) Width and (b) length distribution of the $\mathrm{Zn}_{2} \mathrm{GeO}_{4}$ crystal clusters. 

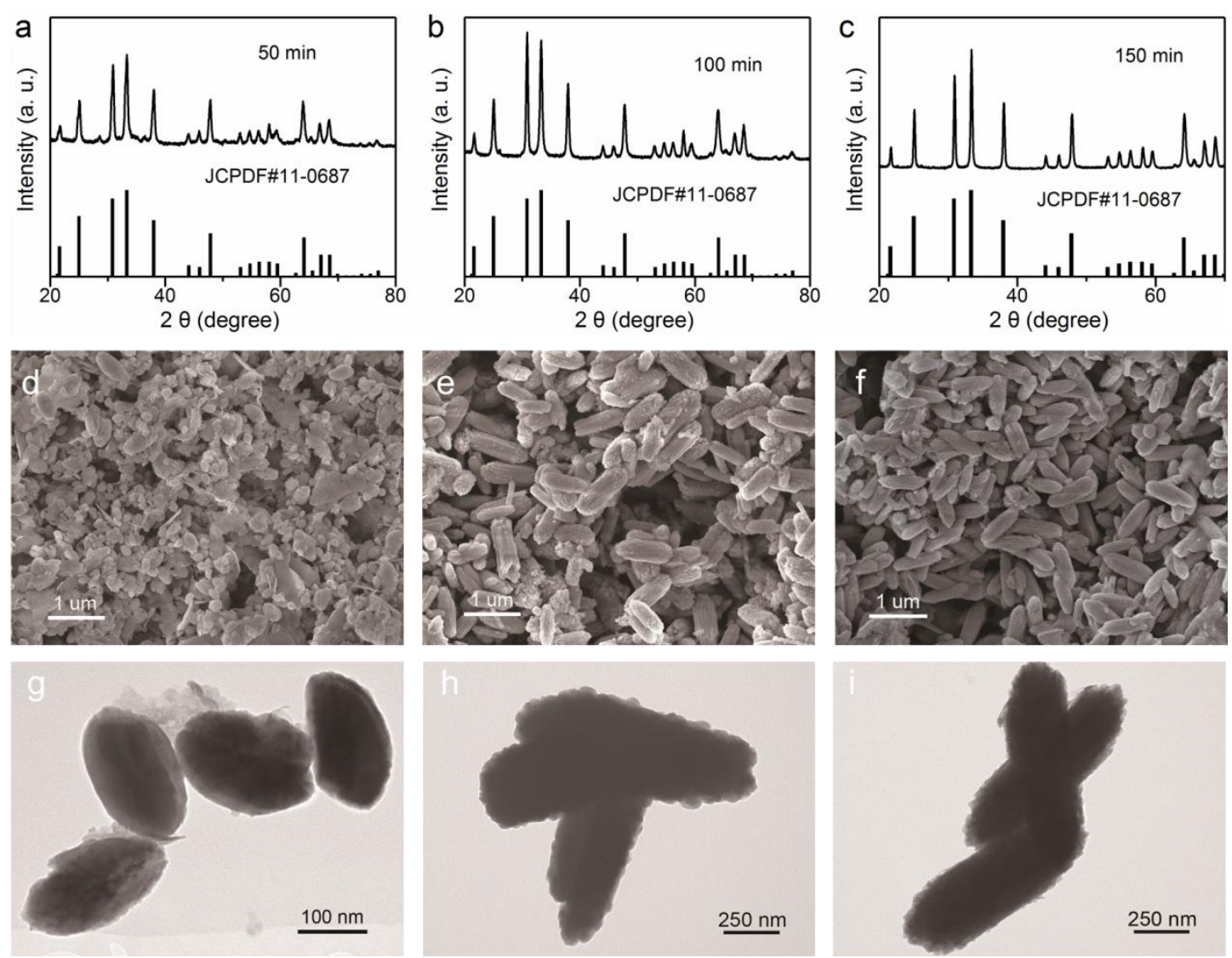

Figure S4. The XRD pattern of $\mathrm{Zn}_{2} \mathrm{GeO}_{4}$ taken out after (a) 50 (b) 100 (c) $150 \mathrm{~min}$, The SEM image of $\mathrm{Zn}_{2} \mathrm{GeO}_{4}$ taken out after (d) 50 (e) 100 (f) $150 \mathrm{~min}$, The TEM image of $\mathrm{Zn}_{2} \mathrm{GeO}_{4}$ taken out after (g) 50 (h) 100 (i) $150 \mathrm{~min}$.
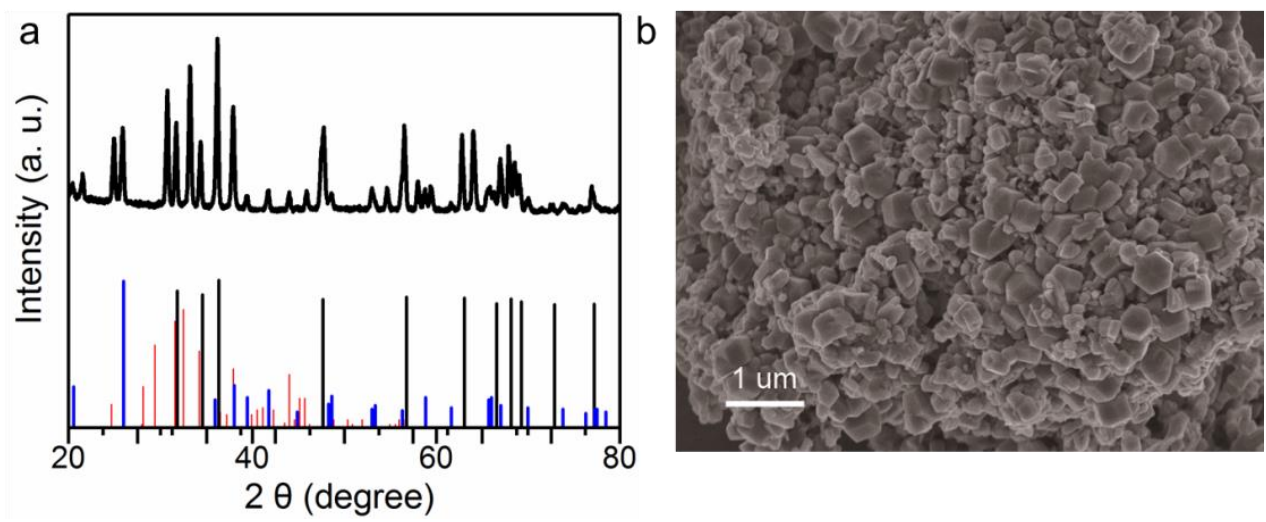

Figure S5. (a) XRD and (b) SEM image of $\mathrm{Zn}_{2} \mathrm{GeO}_{4}$ without $\mathrm{ZnCl}_{2}$. 


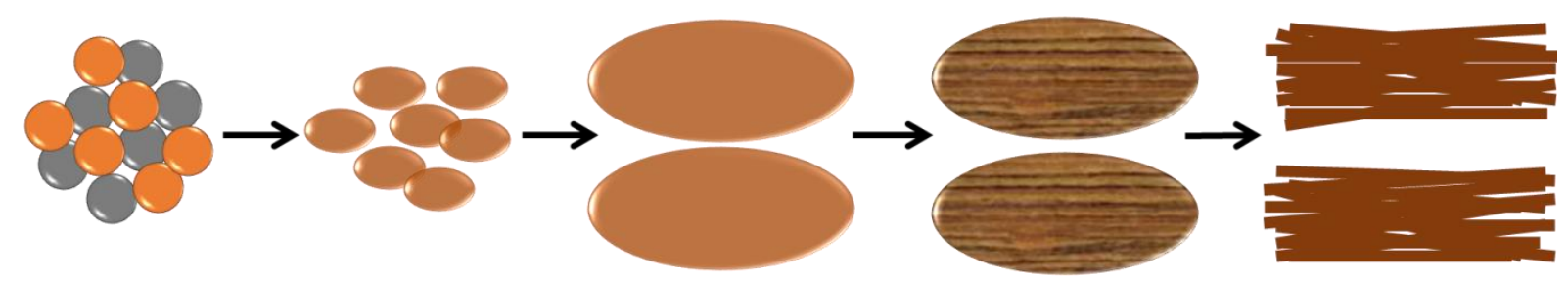

Figure S6. The scheme illustration of growth process of $\mathrm{Zn}_{2} \mathrm{GeO}_{4}$ crystal clusters.
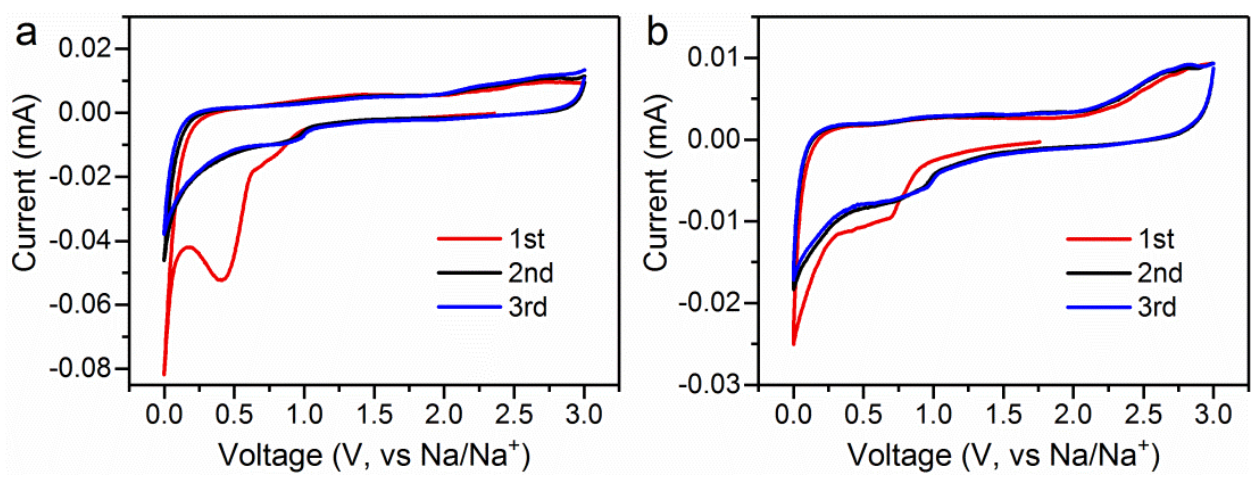

Figure S7. CV curves of (a) $\mathrm{GeO}_{2}$ (b) $\mathrm{ZnO}$ between the voltage of $0.01-3 \mathrm{~V}$ at the scan rate of $0.1 \mathrm{mV} \mathrm{s}^{-1}$.
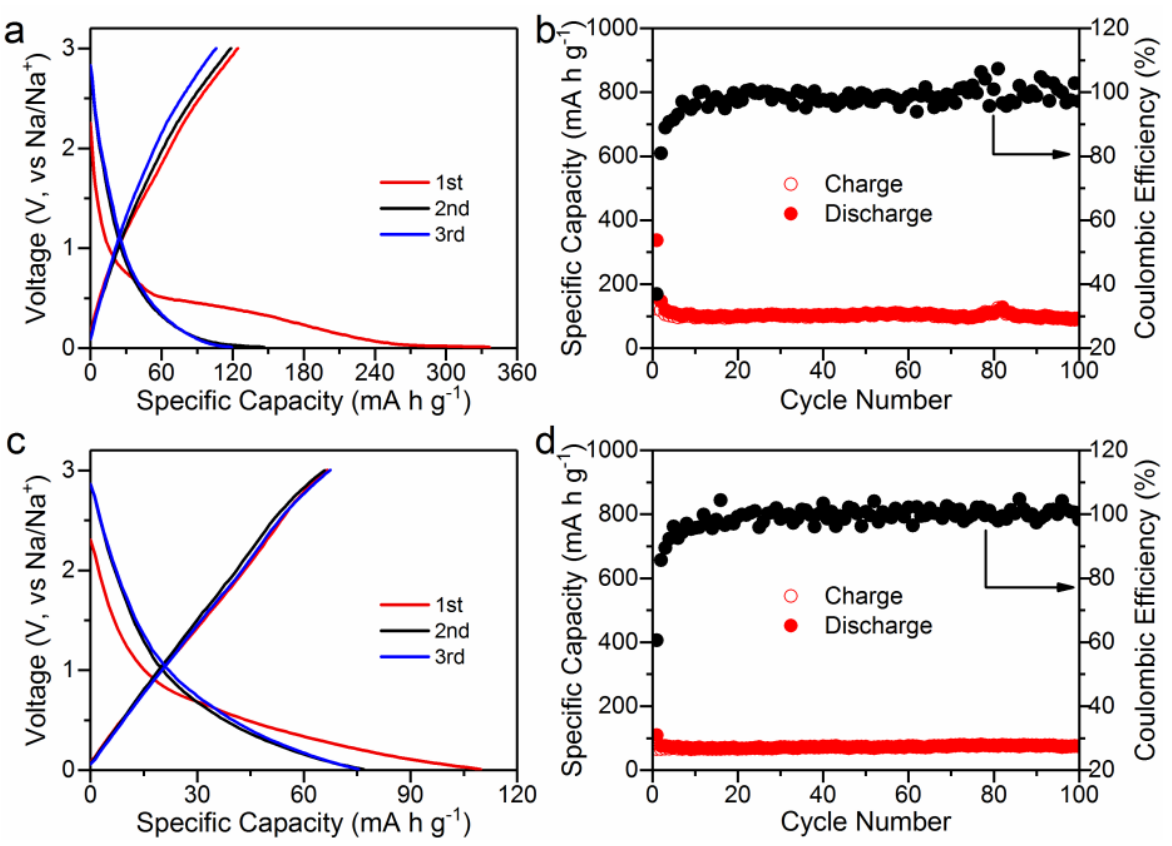

Figure S8. (a) Voltage profile and (b) the cycling performance of $\mathrm{GeO}_{2}$, (c) Voltage profile and (d) the cycling performance of $\mathrm{ZnO}$ at the current density of $0.1 \mathrm{~A} \mathrm{~g}^{-1}$. 


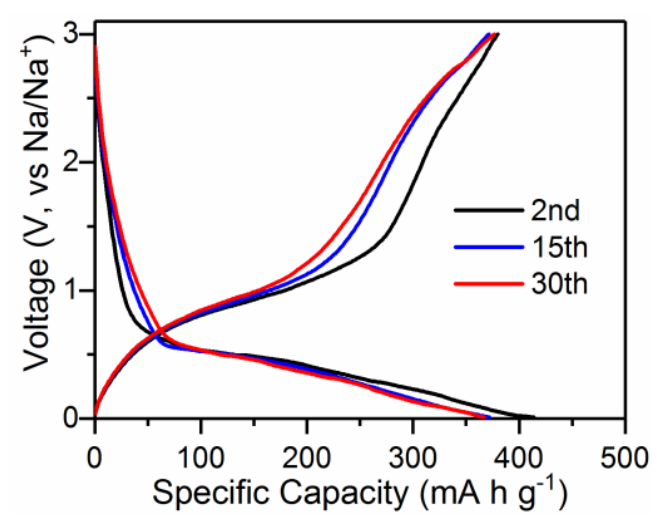

Figure S9. The voltage profiles of $\mathrm{Zn}_{2} \mathrm{GeO}_{4}$ at the $2^{\text {nd }}, 15^{\text {th }}$ and $30^{\text {th }}$ cycles.

a

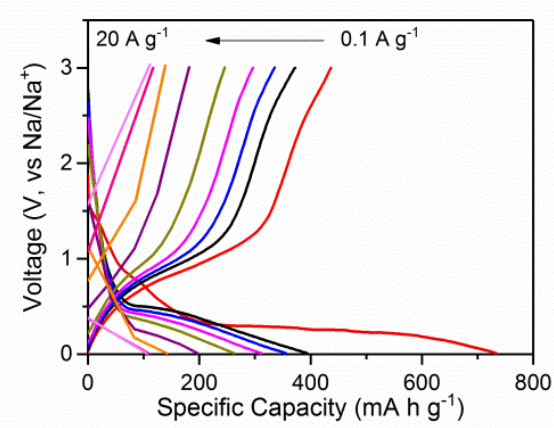

C

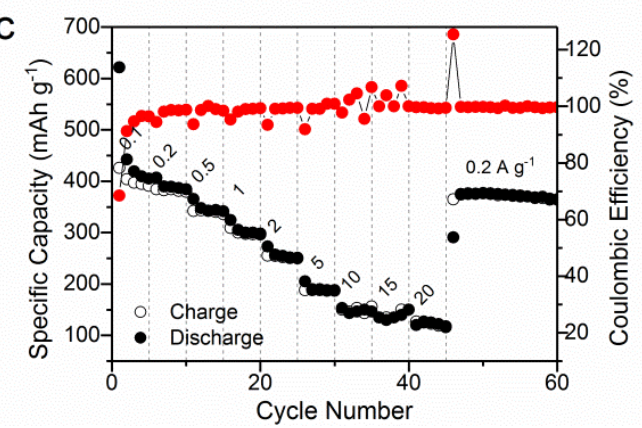

b

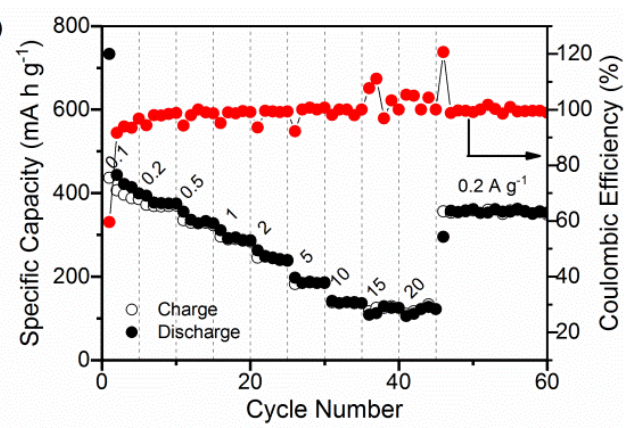

d

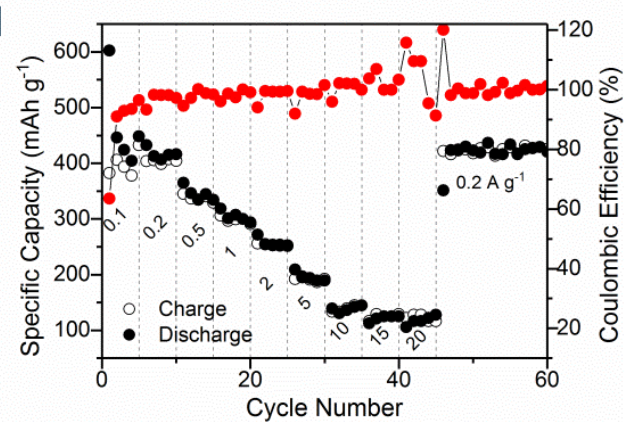

Figure S10. (a) The voltage profiles of the $\mathrm{Zn}_{2} \mathrm{GeO}_{4}$ at the different current density. (b-c) Rate performance of the $\mathrm{Zn}_{2} \mathrm{GeO}_{4}$ with the three different batteries to present the reproducibility of the testing results. 

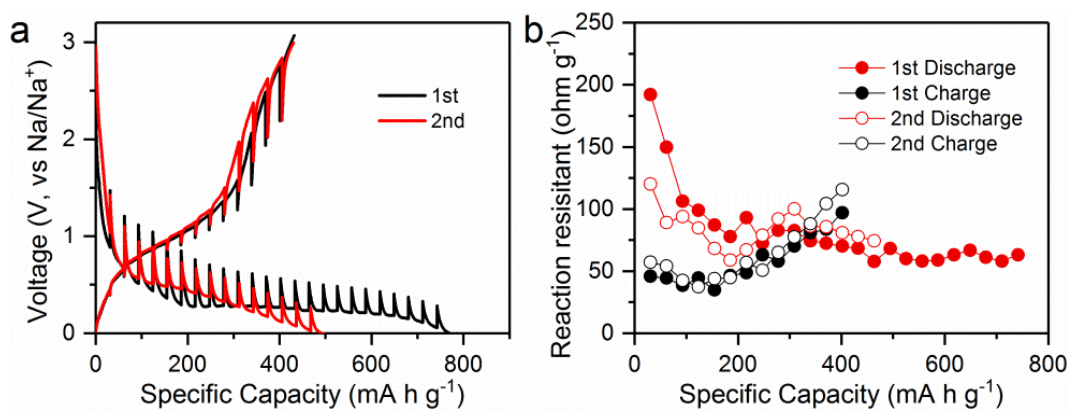

Figure S11. (a) The GITT profiles for the first two cycles and (b) the corresponding reaction resistant.
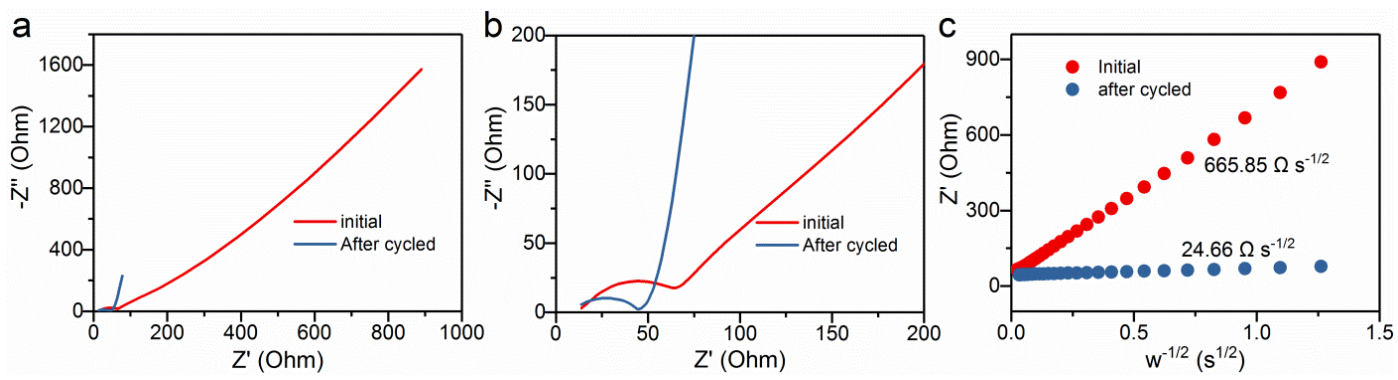

Figure S12. (a-b) The Nyquist plots of $\mathrm{Zn}_{2} \mathrm{GeO}_{4}$ before and after the first cycles. (c) The corresponding liner fits (relationship between $\mathrm{Z}^{\prime}$ and $\omega^{-1 / 2}$ ) in low-frequency region

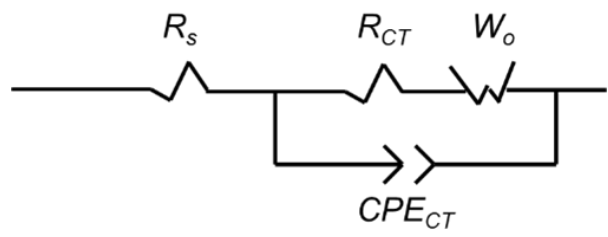

Figure S13. The equivalent circuit of Nyquist plots of $\mathrm{Zn}_{2} \mathrm{GeO}_{4}$.
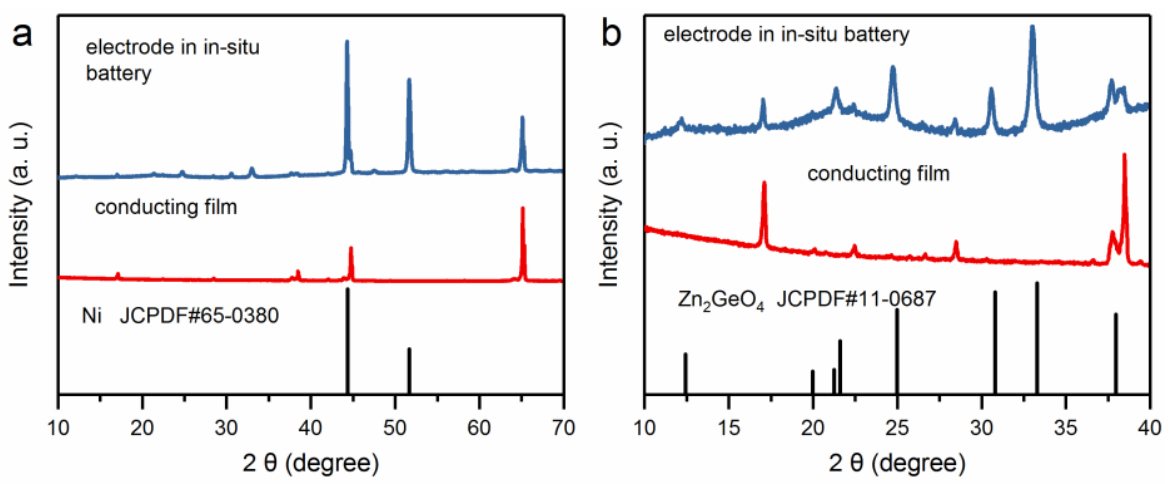

Figure S14. XRD patterns of (a) the in-situ cell at the degree of $10-70^{\circ}$ (b) the in-situ cell at the degree of $10-40^{\circ}$ 
Table S1: the a-lattice and c-lattice parameter of the $\mathrm{Zn}_{2} \mathrm{GeO}_{4}$ unit cell.

Based on the Bragg equation: $2 \mathrm{~d} \sin \theta=\lambda$

For hexagonal crystal system: $\mathrm{d}=\frac{a}{\sqrt{\frac{4}{3}\left(h^{2}+h k+k^{2}\right)+\frac{l^{2}}{\left(\frac{c}{a}\right)^{2}}}}$

\begin{tabular}{|c|c|c|c|c|}
\hline $\begin{array}{c}\text { Discharge } \\
\text { voltage }(\mathrm{V})\end{array}$ & $\begin{array}{c}\text { Peak of }(410) \\
(2 \theta)\end{array}$ & $\begin{array}{c}\text { Peak of }(113) \\
(2 \theta)\end{array}$ & $\begin{array}{c}\text { a-lattice } \\
(\AA)\end{array}$ & $\begin{array}{c}\text { c-lattice } \\
(\AA)\end{array}$ \\
\hline 1.41 & 33.02 & 30.56 & 14.3542 & 9.6101 \\
\hline 0.85 & 32.98 & 30.60 & 14.3711 & 9.5931 \\
\hline 0.69 & 32.96 & 30.60 & 14.3796 & 9.5920 \\
\hline 0.57 & 32.94 & 30.58 & 14.3881 & 9.5982 \\
\hline 0.45 & 32.92 & 30.58 & 14.3966 & 9.5971 \\
\hline 0.41 & 32.90 & 30.58 & 14.4051 & 9.5960 \\
\hline 0.38 & 32.78 & 30.52 & 14.4564 & 9.6113 \\
\hline 0.35 & 32.72 & 30.56 & 14.4822 & 9.5933 \\
\hline
\end{tabular}
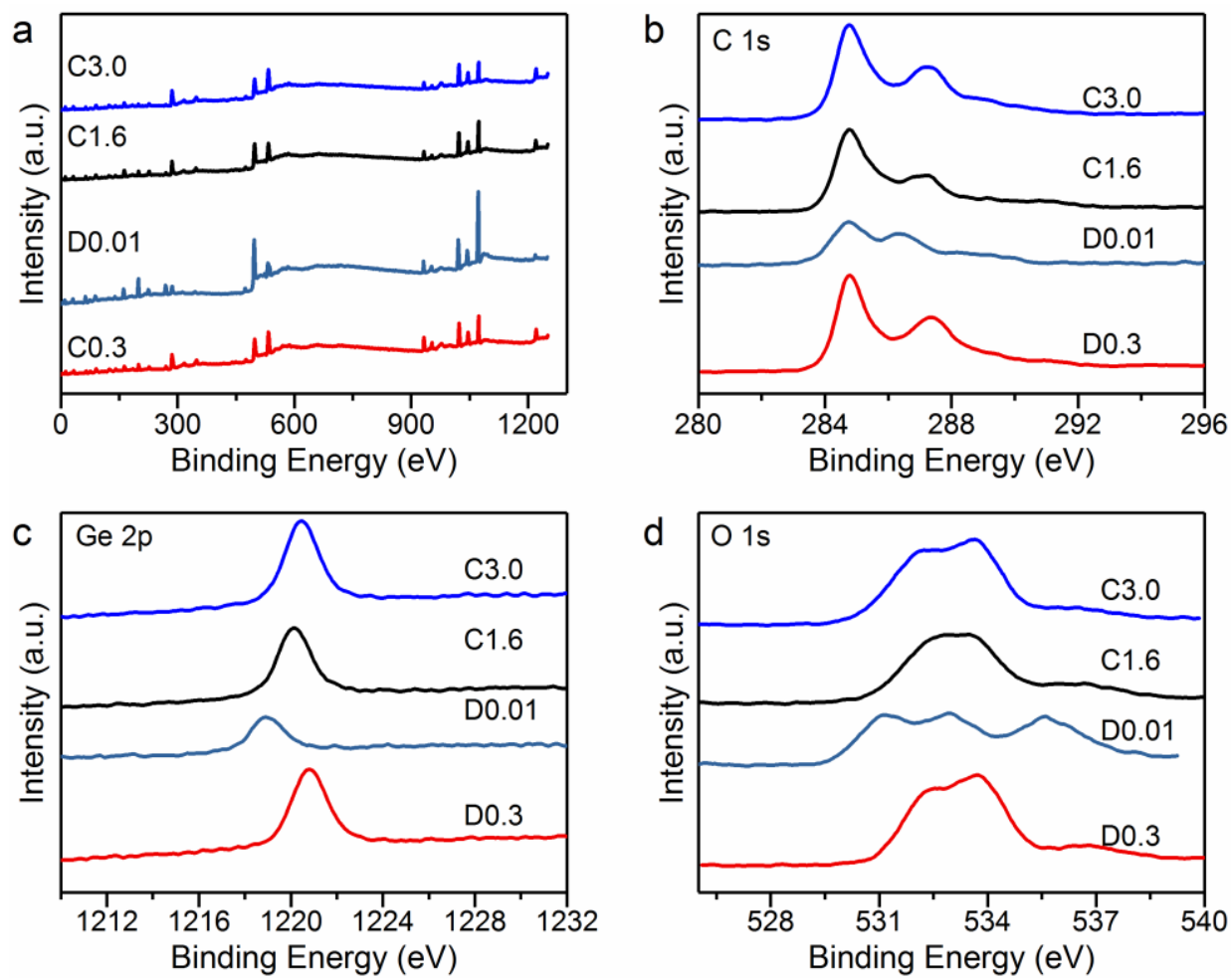

Figure S15. The XPS spectrum at the different voltage during the 1st cycle (a) full XPS spectrum of $\mathrm{Zn}_{2} \mathrm{GeO}_{4}$ and high resolution XPS core-level (b) C 1s (c) Ge 2p (d) O 1s 


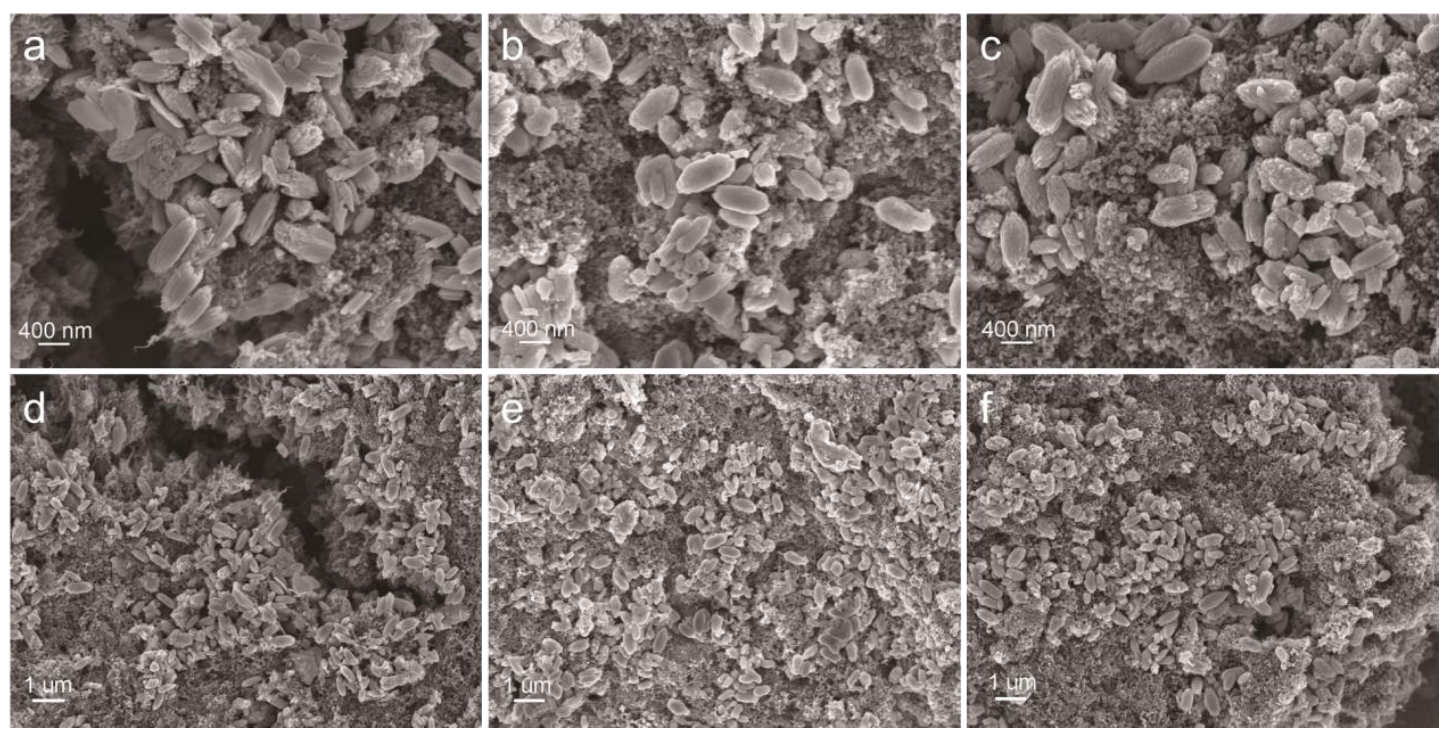

Figure S16. SEM images of $\mathrm{Zn}_{2} \mathrm{GeO}_{4}$ electrode at different electrochemical process of 1st cycle (a d) initial (b e) after discharge (c f) after charge
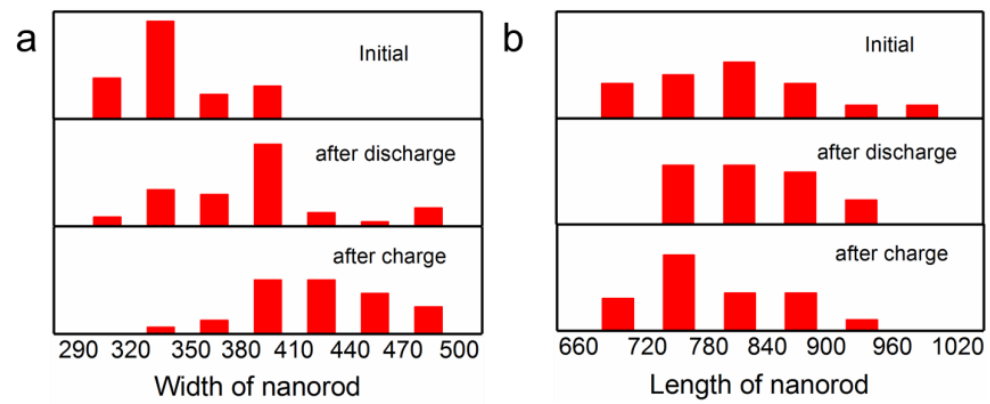

Figure S17. (a) the diameter and (b) the length of $\mathrm{Zn}_{2} \mathrm{GeO}_{4}$ at different electrochemical process of 1 st cycle

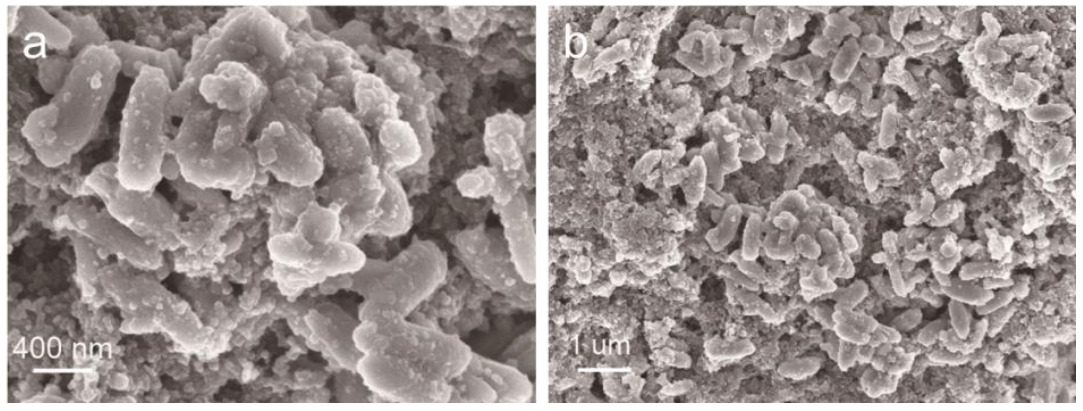

Figure S18. $(\mathrm{a}, \mathrm{b}) \mathrm{SEM}$ images of the $\mathrm{Zn}_{2} \mathrm{GeO}_{4}$ after 450 cycles. 
a1

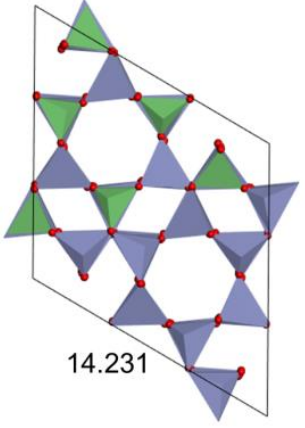

$\mathrm{Zn}_{2} \mathrm{GeO}_{4}$ $b_{1}$

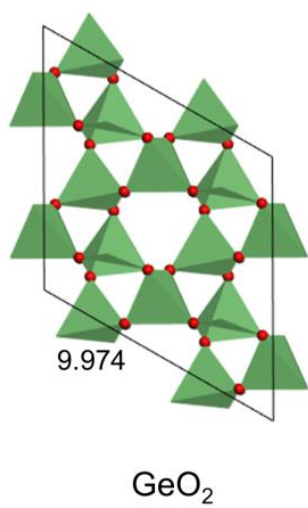

C1

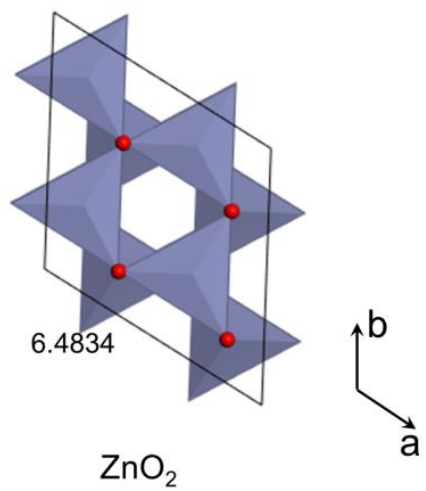

a2

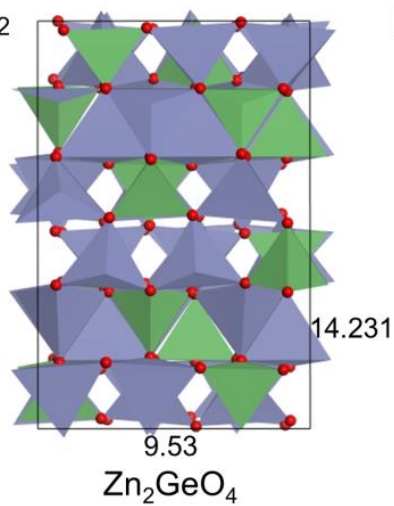

b2

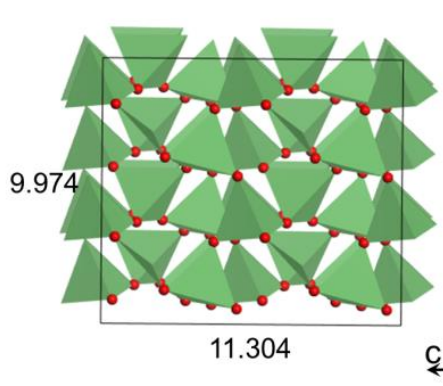

$\mathrm{GeO}_{2}$
$\mathrm{C} 2$

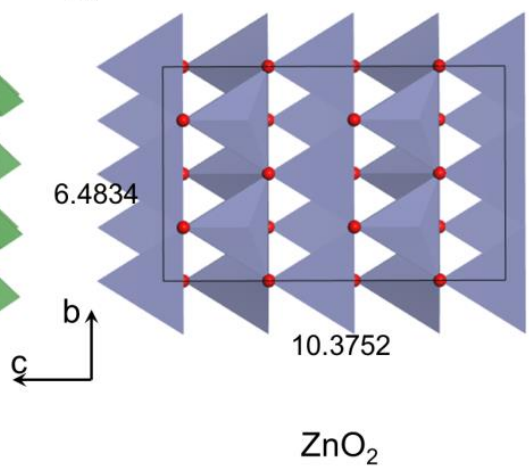

a3

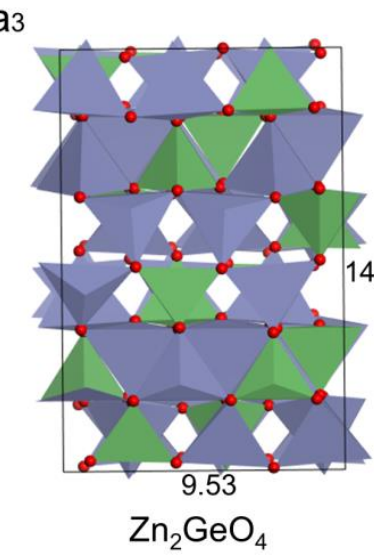

b3

C3

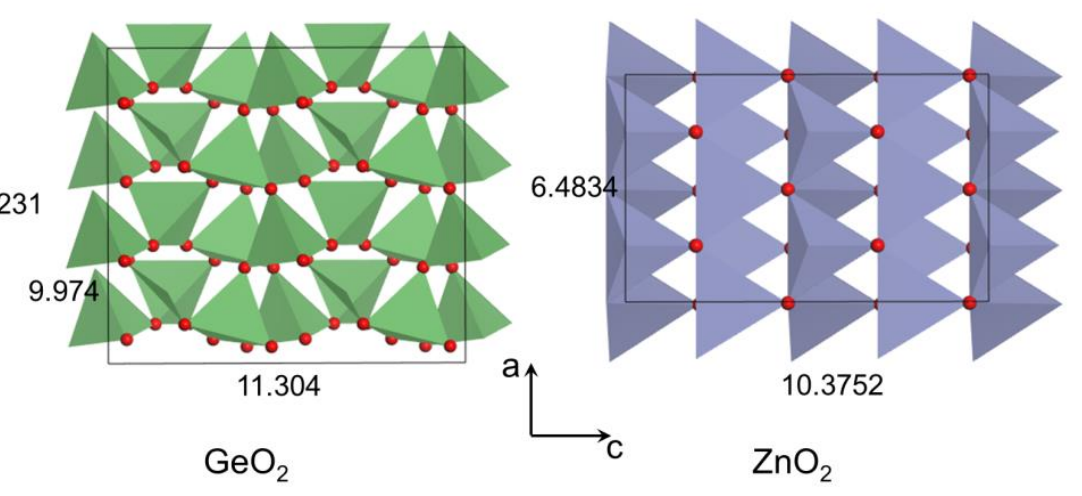

Figure S19. Illustration of the improved Na-ion storage performance of $\mathrm{Zn}_{2} \mathrm{GeO}_{4}$ compared with $\mathrm{GeO}_{2}$ and $\mathrm{ZnO}_{2}$ in terms of crystal structure. (a1-c1) (001) crystal plane (a2-c2) (100) crystal plane (a3-c3) (010) crystal plane 


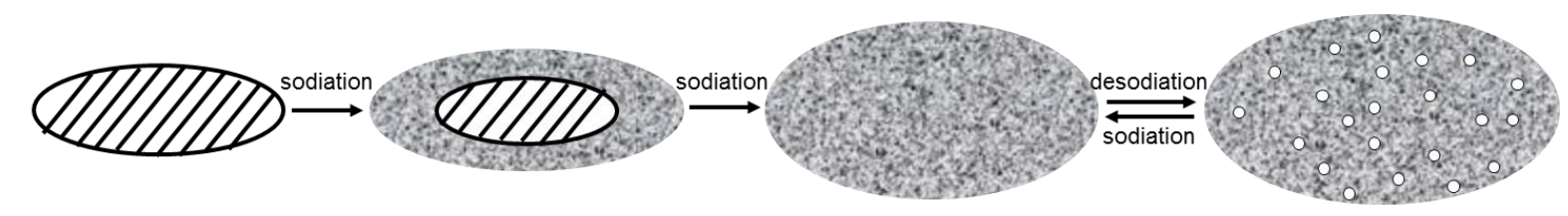

\section{Crystal $\mathrm{Zn}_{2} \mathrm{GeO}_{4} \quad$ Surface amorphous Complete amorphous Porous structure with voluminal expansion with further expansion}

Figure S20. Schematic diagrams of the step-by-step sodiation process of $\mathrm{Zn}_{2} \mathrm{GeO}_{4}$.
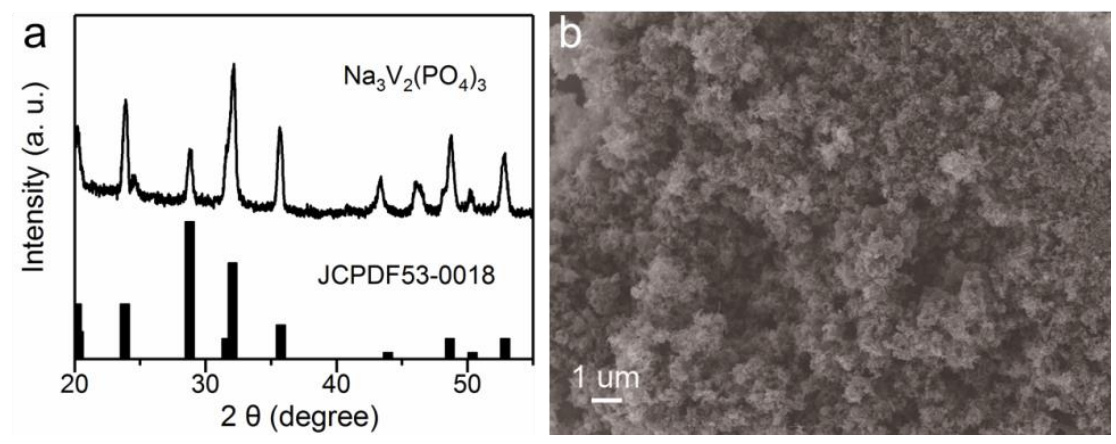

Figure S21. (a) The XRD pattern and (b) the SEM image of $\mathrm{Na}_{3} \mathrm{~V}_{2}\left(\mathrm{PO}_{4}\right)_{3} / \mathrm{C}$ nanoparticles.
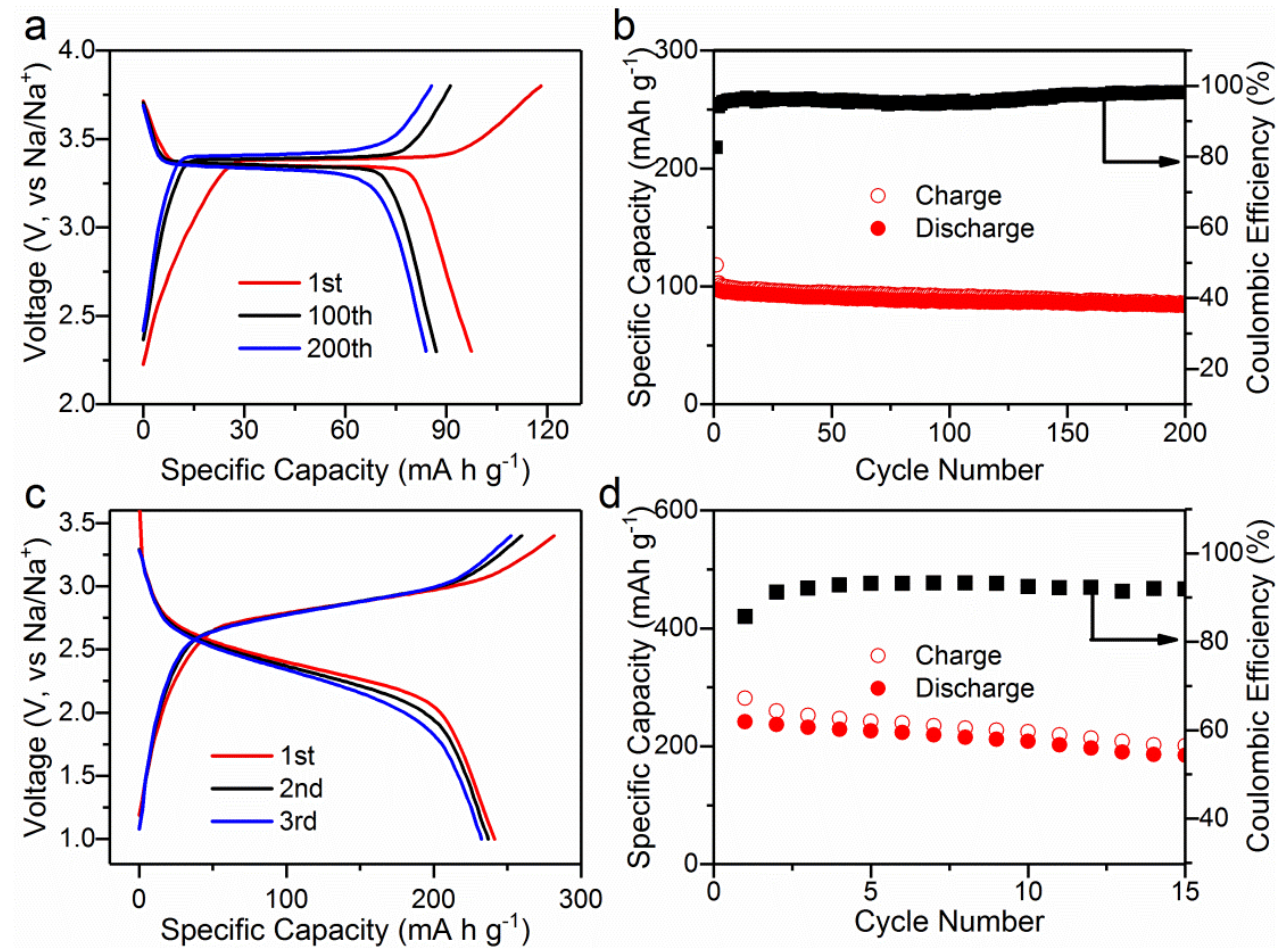

Figure S22. (a) Voltage profiles of $\mathrm{Na}_{3} \mathrm{~V}_{2}\left(\mathrm{PO}_{4}\right)_{3} / \mathrm{C}$ nanoparticles at $0.1 \mathrm{~A} \mathrm{~g}^{-1}$ (b) cycling performance at $0.1 \mathrm{~A} \mathrm{~g}^{-1}$. (c) Voltage profiles and (d) cycling performance of full cell. 
Table R1. The detailed performance comparison table of metal oxides in sodium-ion battery with the previous literatures.

\begin{tabular}{|c|c|c|c|}
\hline Metal oxide & Current density $\left(\mathrm{A} \mathrm{g}^{-1}\right)$ & Capacity $\left(\mathrm{mA} \mathrm{h} \mathrm{g}^{-1}\right)$ & Ref \\
\hline $\mathrm{Zn}_{2} \mathrm{GeO}_{4}$ & 20 & 111.1 & This work \\
\hline $\mathrm{ZnSnO}_{3}$ hollow cubes & 0.48 & $\sim 100$ & $\begin{array}{c}\text { J. Mater. Chem. A, } \\
2015,3,14033\end{array}$ \\
\hline $\mathrm{Zn}_{2} \mathrm{GeO}_{4}$ nanowires & 0.5 & 256 & $\begin{array}{c}\text { J. Mater. Chem. A, } \\
2016,4,10691\end{array}$ \\
\hline $\mathrm{Zn}_{2} \mathrm{SnO}_{4}$ nanowires & 1.6 & 201 & $\begin{array}{c}\text { J. Mater. Chem. A, } \\
\text { 2016, 4, 10691 }\end{array}$ \\
\hline $\begin{array}{c}\text { hybrid 3D-0D } \\
\text { graphene-Fe }\end{array}$ & 5 & 62 & $\begin{array}{c}\text { ACS Appl. Mater. } \\
\text { Interfaces 2016, 8, } \\
26878\end{array}$ \\
\hline \begin{tabular}{c}
$\mathrm{GF}+\mathrm{V}_{2} \mathrm{O}_{3} / \mathrm{CNTs}$ \\
\hline
\end{tabular} & 10 & 207 & small 2016, 12, 3048 \\
\hline
\end{tabular}

